\title{
The Construction of Shandong Economic Climate Index and its Application
}

\author{
Rui Guo ${ }^{1}$, Yongfu Cao ${ }^{2}$ \\ ${ }^{1)}$ School of Management, Qilu Normal University, Jinan, Shandong, China (guorui228@ 126.com) \\ ${ }^{2)}$ Institute of World Economics and Politics Chinese Academy of Social Sciences, Beijing, China (caoyongfu@ yeah.net)
}

\begin{abstract}
To facilitate regional economic monitor, this paper constructs economic climate index of Shandong province using frequency filter method. The main analysis findings include: The economy of Shandong is more stable comparing with Guangdong, Jiangsu and Zhejiang; the economic fluctuation of Shandong is highly synchronized with China, while Guangdong, Jiangsu and Zhejiang lead the national fluctuation; the economic fluctuation of Shandong is highly correlated with other provinces around Bohai Sea, and it has much similarity with Liaoning province.
\end{abstract}

Keywords - economic climate index, frequency filter, regional economy

\section{山东经济景气指数的构建及其运行特征}

\author{
郭锐 $^{1} \quad$ 曹永福 $^{2}$ \\ 1)齐鲁师范学院管理学院, 济南, 山东, 中国 \\ 2) 中国社科院世界经济与政治研究所，北京，中国
}

摘 要 本文采用频域滤波方法构建山东省经济景气指数, 为区域经济监测提供了重要工具。统计分析表明, 与粤、苏、浙等东 南沿海经济大省以及中西部省份相比, 山东经济的内在稳定性较强; 山东的经济波动与全国高度相关, 而且从时序上是同步的, 而粤、 苏、浙等省份则对全国有时序领先性；山东与环渤海经济圈省份的波动协同性较强，波动特征与辽宁较为接近。

关键词 景气指数, 频域滤波, 区域经济

\section{1. 引言}

2012 年山东省 GDP 总量超过 5 万亿元, 占全国的 $9.6 \%$, 在全国排名第 3; 此外, 山东还是仅次于广东的第 2 人口大省。山东在全国、尤其是在环渤海经济圈中的地位 越来越重要, 其经济运行特点值得关注。

在研究区域经济波动时, GDP 是重要的综合指标, 如 孙天琦 (2004) 就是采用年度 GDP 数据分析各省经济景气 与全国的同步性, 但 GDP 指标的频率为年度或季度, 统计 时滞较长, 而且经常需要根据新的资料做出修订, 与月度 数据相比及时性有所欠缺。国家统计局公布了各省的企业 景气指数, 对于区域经济监测有一定帮助, 但是该指数也 是频率较低的季度数据; 而且这种指数的基础是对企业信 心的问卷调查, 是基于定性判断而并非统计数据, 不可避 免地受到企业管理层主观心理感受波动的影响。

在分析区域宏观经济波动时, 各个指标之间波动趋势
往往不尽一致, 难以根据单一指标判断形势; 每个指标往 往都会有统计误差, 更加大了信息分析的难度。因此, 比 较合理的方法是根据月度统计数据构建区域经济景气指 数, 通过信息汇总克服单指标的缺陷。中国经济景气监测 中心和大型企业联合会等机构制定了全国层面的经济景气 指数, 但是目前区域层面的研究还相对薄弱。这方面国外 已经有一定经验, 如美联储费城分行制定了各州的同步景 气指数, Owyang (2005) 等曾经利用该指数研究美国各州 经济周期阶段的差异性。国内学者张文涁（2012）构建了 分省的经济景气指数, 但是其研究侧重于最新计量分析方 法的应用 (如多因子动态模型、马儿科夫区制转换模型等), 在区域经济特点、变量选取等细节方面着墨较少。

根据作者收集的文献, 尚没有针对山东这一人口、经 济大省的经济景气指数研究, 这是本文的切入点。作者采 用 OECD 等国际组织的通行做法, 通过详尽的数据梳理和 
分析, 构建山东经济景气指数, 为区域经济监测提供了重 要工具。然后, 在此基础上分析山东经济波动的特点, 并 与全国其他省份, 尤其是粤苏浙、环渤海经济圈等省份进 行比较。

本文结构安排如下: 第 2 部分构建山东省月度经济景 气指数, 经过综合分析, 决定选择工业增加值、发电量、 地方预算财政收入、进出口总额共 4 个指标加总得到景气 指数; 第 3 部分对山东以及其他省份的经济景气指数波动 曲线做出初步观察; 第 4 部分从山东景气指数与全国协动 性、波动性、区域关联性等方面分析山东经济波动的特征; 第 5 部分做出小结。

\section{2. 山东区域景气指数的构建方法}

按照 OECD 的实践作法, 构建综合景气指数主要包括 4 个步骤: (1) 指标初选, 需要选择构成综合指数的备选 指标, 并确定经济周期基准指标; (2) 指标退势 (De-trend), 这是数据处理的关键环节, 其思路是剔除指标的长期趋势 项, 保留周期性波动成分; (3) 指标篎选, 一般是分析备 选指标和基准指标之间的交叉相关系数, 然后根据指标的 重要性、数据统计质量等因素选择指标进入综合指数; (4) 指标合成, 将筛选出的指标按照一定原则进行加总, 得到 综合景气指数。下面将按照介绍本文的作法。

\section{1 指标初选}

与全国层面相比, 选择区域经济景气备选指标时的最 大挑战是数据的连续性和可获得性。美联储费城分行在制 定区域经济指数时主要集中于月度就业数据, 分别为: 非 农就业人数、制造业总工作小时数、失业率、工资, 美国 这些就业数据的统计非常及时。中国的就业统计相对比较 薄弱、滞后, 难以借鉴美联储费城分行的模式。

作者首先收集了 11 个常见的备选指标, 分别是: 工业 增加值、工业品产销率、社会消费品零售总额、固定资产 投资、房地产开发投资、发电量、货运量、地方财政预算 收入、金融机构贷款余额、进口额、出口额。这些指标涵 盖了生产、消费、投资、运输、财政、金融、贸易等各个 方面。对于经济周期基准指标, 作者仍然选择最常用的综 合指标季度 GDP。时间区间为 2001 年 1 月 2013 年 5 月, 涵盖了中国市场经济体制基本建立之后的时期。数据来源 于中经网数据库、华通人数据库和山东统计信息网。

如果要衡量实际变动, 应剔除价格因素。但因为地区 层面的价格缩减指数非常不健全, 本文直接采用名义值构 建指数, 与实际值相比, 名义值反映主体的货币交易, 也 有其重要的经济含义。作者对所有的指标均取自然对数, 为了克服变量的季节变动, 在 Eviews5.0 软件中采用 Census
X12 方法进行季调, 保留下趋势项和周期性波动成分。

\section{2 指标退势（De-trend）}

在经济学界 HP 滤波和频域滤波是常用工具。HP 滤波 的思想是寻找变量的趋势, 算法是在数据对趋势偏离的程 度和趋势本身的波动程度之间作出最优化选择。从实际应 用来看, HP 滤波仍然会保留大量噪音。

经过权衡, 本文采用频率滤波, 其思路是假设时间序 列由不同频率 (周期) 的余弦函数组成, 采用一定算法将 周期为 $1.5 \sim 10$ 年的函数提取加总，认为周期小于 1.5 年的 波动属于短期噪音和季节波动, 周期大于 10 年的波动则为 长期趋势。频率滤波有多种形式, 本文采用非对称 CF 滤 波器 (Christiano-Fitzgerald) 进行处理, 与其他频域滤波相 比, 其最大优点是可以不丧失样本观测值。

\section{3 指标篮选及其解释}

表 1 列出了各个备选指标与 GDP 之间的领先、滞后相 关系数, 周期相关性较强的指标用黑体和下划线标出。可 以发现山东省的工业增加值、发电量、地方预算财政收入、 出口额、进口额这 5 个指标与基准指标高度相关, 结果符 合经济学直觉。工业增加值反映了制造业对于经济运行的 重要性, 发电量则反映了各种经济活动的能源需求, 地方 预算收入对经济波动高度敏感, 尽管山东的外贸依存度低 于东南沿海省份, 但是对外贸易与省内经济仍然是高度关 联的。

\begin{tabular}{|c|c|c|c|c|c|}
\hline 指标 & -2 & -1 & 0 & 1 & 2 \\
\hline 工业增加值 & -0.29 & 0.09 & $\underline{\mathbf{0 . 7 6}}$ & 0.70 & 0.46 \\
\hline 工业品产销率 & 0.36 & 0.29 & 0.18 & 0.09 & 0.04 \\
\hline 社会消费品零售 & 0.07 & 0.25 & 0.34 & 0.27 & 0.12 \\
\hline 固定资产投资 & -0.07 & 0.02 & 0.10 & 0.09 & 0.03 \\
\hline 房地产投资额 & -0.12 & 0.13 & 0.34 & 0.42 & 0.33 \\
\hline 发电量 & -0.15 & 0.20 & $\underline{\mathbf{0 . 8 0}}$ & 0.78 & 0.50 \\
\hline 货运量 & -0.42 & -0.10 & 0.18 & 0.31 & 0.27 \\
\hline 地方预算财政收 & 0.17 & 0.48 & $\underline{\mathbf{0 . 7 6}}$ & 0.70 & 0.65 \\
\hline 银行贷款余额 & -0.67 & -0.57 & -0.35 & -0.06 & 0.26 \\
\hline 出口额 & 0.38 & 0.74 & $\underline{\mathbf{0 . 9 1}}$ & 0.87 & 0.63 \\
\hline 进口额 & 0.13 & 0.57 & $\underline{\mathbf{0 . 8 6}}$ & 0.80 & 0.67 \\
\hline
\end{tabular}

表 1 备选指标与 GDP 的交叉相关系数

社会消费品零售总额与固定资产投资这个指标没有表 现出明显的周期相关性, 值得注意。社会消费品零售总额 
可以大致代表居民消费（从统计上也包括社会集团购买的 消费品), 而居民消费往往较为平滑, 不一定随着经济周期 波动而大起大落, 未表现出周期敏感性是可以理解的; 固 定资产投资的口径较宽，包括大量政策性、财政性投资, 因此也不一定会随着经济周期波动而同步波动。房地产投 资额与经济周期基准指标相关程度为中等, 不纳入指数。

进口和出口均与有重要经济含义, 但是在加工大量存 在的背景下, 进口、出口之间有严重信息重合, 作者采用 进出口总额指标。最终本文将工业增加值、发电量、地方 预算财政收入、进出口总额共 4 个指标的滤波数据纳入经 济景气合成指数。这一点与其他学者的做法有所区别, 如 张文涁 (2012) 在构建区域景气指数时采用了工业增加值、 社会消费品零售总额、出口共 3 个指标。

\section{4 指标合成}

在指标合成时需要考虑变量的经济重要性、波动性等 因素, 本文根据变量与基准指标的相关系数大小来确定指 标权重, 周期敏感性越强的指标权重越大。经计算, 上述 4 个指标的权重分别为 $0.24 、 0.25 、 0.23 、 0.28$, 加总得到 山东经济景气合成指数。

\section{3. 对山东与其他省份经济景气指数曲线的初步观察}

在构建山东经济景气指数之后, 作者收集了全国以及 30 个省、自治区和直辖市的工业增加值、发电量、地方预 算财政收入、进出口总额数据 (西藏数据缺失较多, 暂时 未纳入), 比照山东省的计算步骤得到全国以及区域经济景 气指数。严格来讲各个省市的指标设置和权重应单独进行 分析, 但上述 4 个指标的经济重要性都很强, 直接构建景 气指数有其合理性, 而且这样处理更有利于省际比较。

在构建省份和全国的经济景气指数之后, 作者选择山 东、浙江、内蒙古 3 个省、自治区的波动曲线进行初步观 察和比较 (图 1)。

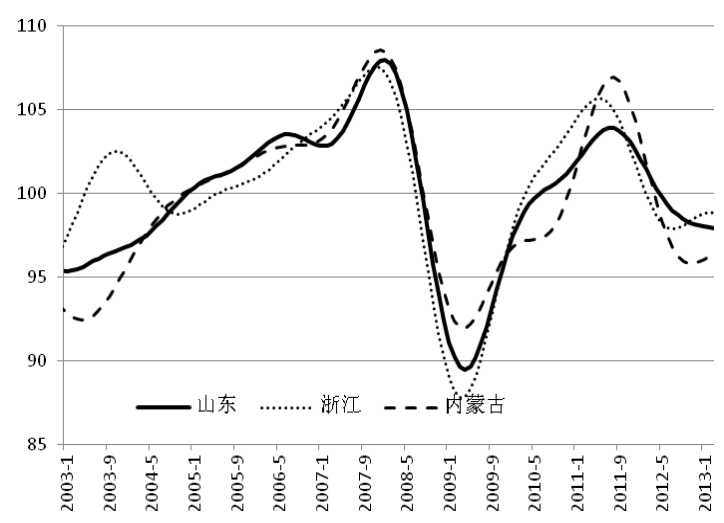

图 1 山东、浙江、内蒙古景气指数波动曲线比较
各个省份的波动一定相似性, 如 2008 年金融危机对各 个省份都产生了剧烈冲击, 2009 年之后都出现强劲反弹。 但是各个省份的波动特点也有差别: 如浙江在 2003 年曾经 出现了一次剧烈起伏, 其他两省份并没有出现; 内蒙古的 经济复苏在 2011 年显著加速, 这也与其他省份有所区别。

可见全国各省份的景气波动并非整齐划一, 有必要进 行具体分析。下文主要从经济景气的协动性、波动性进行 省际比较, 并关注山东与环渤海地区省份、周边省份的波 动关联性, 从而分析山东省的波动特征。

\section{4. 山东经济波动特点及其省际比较}

\section{1 山东与全国经济景气波动的协同性及其时序关系}

作者计算了各省与全国景气波动的交叉相关系数, 并 且列出了其领先 (滞后) 期。从表 2 左半部分可以看出, 江苏、广东、浙江、福建等东南沿海省份与全国的景气波 动高度相关, 相关系数均在 0.95 以上; 山东省与全国的经 济相关系数为 0.93 , 在全国 30 个省市中排名第 6 , 也属于 与全国高度协同的省份; 相比之下, 西部省份则与全国的 协同性较低, 这些省份自身的特定因素会对其经济波动产 生显著影响。

表 2 右半部分列出了各省与全国相关系数的领先、滞 后期, 符号为正则说明领先全国, 符号为负则说明滞后于 全国, 数值为 0 则说明与全国同步相关。可以看出, 山东 与全国不仅从数值上是高度相关的, 而且从时序上是同步

\begin{tabular}{|c|c|c|c||c|c|c|c|}
\hline 省份 & $\begin{array}{c}\text { 相关系 } \\
\text { 数 }\end{array}$ & 省份 & $\begin{array}{c}\text { 相关系 } \\
\text { 数 }\end{array}$ & 省份 & $\begin{array}{c}\text { 领先滞 } \\
\text { 后期 }\end{array}$ & 省份 & $\begin{array}{c}\text { 领先滞 } \\
\text { 后期 }\end{array}$ \\
\hline 江苏 & 0.98 & 天津 & 0.85 & 江苏 & 1 & 海南 & 0 \\
\hline 广东 & 0.97 & 宁夏 & 0.85 & 广东 & 1 & 青海 & 0 \\
\hline 浙江 & 0.95 & 贵州 & 0.84 & 浙江 & 1 & 甘肃 & -1 \\
\hline 福建 & 0.95 & 云南 & 0.84 & 福建 & 1 & 山西 & -1 \\
\hline 辽宁 & 0.94 & 上海 & 0.83 & 山东 & $\mathbf{0}$ & 河北 & -1 \\
\hline 山东 & $\mathbf{0 . 9 3}$ & 内蒙古 & 0.82 & 辽宁 & 0 & 江西 & -1 \\
\hline 山西 & 0.92 & 北京 & 0.81 & 湖南 & 0 & 重庆 & -1 \\
\hline 甘肃 & 0.92 & 安徽 & 0.79 & 天津 & 0 & 内蒙古 & -1 \\
\hline 湖北 & 0.90 & 陕西 & 0.79 & 宁夏 & 0 & 安徽 & -1 \\
\hline 湖南 & 0.90 & 吉林 & 0.76 & 云南 & 0 & 广西 & -1 \\
\hline 河北 & 0.89 & 新疆 & 0.75 & 上海 & 0 & 湖北 & -2 \\
\hline 江西 & 0.88 & 四川 & 0.69 & 北京 & 0 & 黑龙江 & -2 \\
\hline 河南 & 0.88 & 海南 & 0.68 & 陕西 & 0 & 河南 & -3 \\
\hline 黑龙江 & 0.87 & 青海 & 0.64 & 吉林 & 0 & 贵州 & -3 \\
\hline 重庆 & 0.87 & 广西 & 0.48 & 四川 & 0 & 新疆 & -4 \\
\hline
\end{tabular}

表 2 各省份景气指数与全国的相关系数及领先滞后期 (月) 
的, 粤、苏、浙等省份则有一定时序领先性。这些东南沿 海省份的中小企业和民营企业比重较高, 外向型企业比重 大, 对市场形势的反应较为敏感, 能够迅速做出调整, 而 山东不具备上述特征。从宏观经济监测的角度讲, 山东省 则可以跟踪粤、苏、浙等省份的短期数据波动, 作为预判 本省经济走势的参考。

\section{2 山东与其他省份经济景气波动性比较}

下面比较各省经济指数的波动性, 表 3 列出了各省经 济景气指数的标准差, 按照从小到大进行排序。可以发现 山东省的经济波动相对较小, 在 30 个省份中从小到大排名 第 5。比山东波动性更小的省份分别为广西、四川、安徽、 陕西, 这 4 个省份的经济总量相对较小, 而且结合表 2 来 看它们与全国经济波动的协同性较低。山东作为与全国高 度协同的经济大省, 体现出的内在稳定性是非常值得关注 的。

\begin{tabular}{|c|c|c||c|c|c|}
\hline 省份 & 标准差 & 排序 & 省份 & 标准差 & 排序 \\
\hline 广西 & 3.2 & 1 & 海南 & 5.2 & 16 \\
\hline 四川 & 3.6 & 2 & 上海 & 5.3 & 17 \\
\hline 安徽 & 3.6 & 3 & 北京 & 5.3 & 18 \\
\hline 陕西 & 3.7 & 4 & 吉林 & 5.4 & 19 \\
\hline 山东 & 3.9 & 5 & 天津 & 5.4 & 20 \\
\hline 辽宁 & 4.1 & 6 & 江西 & 5.5 & 21 \\
\hline 福建 & 4.1 & 7 & 贵州 & 5.9 & 22 \\
\hline 河北 & 4.3 & 8 & 新疆 & 6.2 & 23 \\
\hline 广东 & 4.3 & 9 & 云南 & 6.5 & 24 \\
\hline 浙江 & 4.4 & 10 & 河南 & 6.6 & 25 \\
\hline 内蒙古 & 4.4 & 11 & 甘肃 & 7.3 & 26 \\
\hline 江苏 & 4.6 & 12 & 重庆 & 7.7 & 27 \\
\hline 湖南 & 4.8 & 13 & 山西 & 7.9 & 28 \\
\hline 黑龙江 & 4.9 & 14 & 青海 & 8.2 & 29 \\
\hline 湖北 & 4.9 & 15 & 宁夏 & 10.3 & 30 \\
\hline
\end{tabular}

表 3 各省份景气指数标准差比较

粤、苏、浙等东南沿海省份的波动性大于山东, 在全 国处于中等。这些省份的外贸依存度较高, 容易受到外部 冲击的影响, 中小企业经常扎堆经营, 冲击的影响面会比 较广泛。全国经济波动最大的省份是甘肃、重庆、山西、 青海、宁夏等中西部省份, 这些地区的经济运行有一定脆 弱性, 如大宗商品价格的波动可能会使得资源型省份的经 济出现剧烈波动, 而政策变动也往往导致中西部省份的投 资出现较大变化, 因此经济运行容易出现大起大落。

\section{3 山东省经济波动与周边省份的协动性}

在分析山东经济与全国的协动性、进行省际波动性比 较之后, 有必要分析山东与周边省份的协动性。以辽宁、 河北、北京、天津、山东组成的环渤海经济圈正在成为全 国最具活力的板块之一, 山东在这个经济圈中举足轻重。 山东与河南、安徽、江苏等省份接壤, 存在密切的人员往 来、资金流动，经济波动协同性值得分析。

作者计算了山东省经济景气指数与上述省份的相关系 数, 从高到底的顺序及数值如下: 辽宁, 0.90 ; 江苏, 0.87 ; 河北, 0.86; 北京, 0.85 ; 河南, 0.79 ; 天津, 0.73 ; 安徽, 0.71 。上述结果印证了环渤海经济圈的存在, 山东与这些 省份的经济波动高度协同; 相比之下山东与内陆接壤的河 南、安徽等省份的相关性较低。

值得注意的是, 山东与辽宁的经济波动协动性较高。 回顾表 2 和表 3 可以看出, 辽宁、山东两省与全国景气指 数的协动性非常相似, 与全国的同步相关系数分别为 0.94 和 0.93 , 排名分别为第 5 和第 6 ; 两省经济景气指数的标 准差也比较接近, 分别为 3.9 和 4.1 , 在全国的排名也是第 5 和第 6 。山东与辽宁之间经济波动的相关性很强, 说明这 两个省份都属于环渤海经济圈, 具有地理位置、资源禀赋、 产业结构等方面的相似性, 两省的宏观经济监测和管理可 以相互借鉴。

\section{5. 小结}

作为北方的沿海经济大省, 山东的经济波动表现出鲜 明特色。山东的经济波动与全国高度相关, 广东、江苏、 浙江等东南沿海省份也与全国高度相关, 它们对全国的经 济波动表现出一定的时序领先性, 而山东省则是同步相关; 山东经济有较强的内在稳定性, 这既区别于波动性处于中 等的粤、苏、浙等省份, 也区别于波动性较大的中西部省 份; 此外本文还印证了环渤海经济圈的存在, 尤其发现山 东与辽宁的经济波动特征非常相似。

本文对山东经济景气指数的构建过程是透明的, 实际 部门可以搜集相关数据, 复制本文的计算过程, 并将其作 为区域经济运行监测的重要工具, 在此基础上可以结合山 东经济的运行特点分析形势变化, 并进行省际比较分析。

\section{参考文献(References)}

[1] Carlino, G., K. Still. Regional income fluctuations: common trend and common cycles. The Review of Economics and Statistics, 2001, 83 (3):446 456.

[2] Owyang, M., J. Piger and H. Wall, Business Cycle Phases in U.S. States, The Review of Economics and Statistics, 2005, 87(4): 604-616.

[3] www.oecd.org/std/41629509.pdf. 